\title{
Water Quality Risk Assessment for the Laoguanhe River of China Using a Stochastic Simulation Method
}

\author{
J. Hu${ }^{1,2}$, L. $\operatorname{Sun}^{1}$, C. H. Li ${ }^{1, *}$, X. Wang ${ }^{1,3}$, X. L. Jia ${ }^{1}$, Y. P. Cai ${ }^{3,4, *}$ \\ ${ }^{1}$ Key Laboratory for Water and Sediment Sciences of the Ministry of Education, School of Environment, Beijing Normal University, Beijing \\ 100875, China \\ ${ }^{2}$ Graduate School of Health Sciences, Hirosaki University, Hirosaki, Aomori 036-8564, Japan \\ ${ }^{3}$ Beijing Engineering Research Center for Watershed Environmental Restoration \& Integrated Ecological Regulation, School of Environment, \\ Beijing Normal University, Beijing 100875, China \\ ${ }^{4}$ State Key Laboratory for Water Environment Simulation, School of Environment, Beijing Normal University, Beijing 100875, China
}

Received 18 October 2016; revised 25 March 2017; accepted 19 April 2017; published online March 122018

\begin{abstract}
The Laoguanhe River is a major tributary of the Danjiang River, which is the source water for the Danjiangkou Reservoir (i.e., the source reservoir for the middle route of the South-to-North Water Diversion Project in China). This study was intended to provide scientific decision support to help manage the water environment in the Laoguanhe River and maintain high water quality levels for the water diversion project. Risk assessment based on water quality simulation was undertaken in this research. The QUAL2Kw model was used to improve the simulations of the water quality in the Laoguanhe River under sparse data conditions. Latin hypercube sampling (LHS) was used to improve flow inputs for QUAL2Kw. The model was used to calculate water quality risks under several scenarios based on a Markov stochastic process to reflect uncertainties. The simulation results indicated that water quality of the downstream sections of the Laoguanhe River could meet the basic requirements for exporting water to the Danjiangkou Reservoir.
\end{abstract}

Keywords: QUAL2Kw, Latin hypercube sampling, Markov analysis, the Laoguanhe River, stochastic simulations, South-to-North Water Diversion Project, China

\section{Introduction}

Along with intensive agricultural activities and rapid urbanization and industrialization, issues of poor water quality caused by uncontrolled anthropogenic activities have gradually become an obstacle preventing sustainable development for human beings. As stated by many researchers, one of the core water quality problems is that, especially in developing areas, large amounts of agricultural, municipal and industrial wastewater are being discharged into natural water bodies, resulting in the degeneration of water quality and the inability to meet the water demands of end users,such as local residents, industry, and the environment (Cohen et al., 2004; Cai et al., 2009, 2011a,b; Tan et al., 2011a,b; Huang and Cao, 2011; Liu et al., 2017). Currently, water quality is a serious issue, especially for drinking water source areas. Rivers suffering from the effects of anthropogenic activities because of contained pollut-

\footnotetext{
* Corresponding author. Tel.: +8610 58802928; fax: +86 1058802928.

E-mail address: chunhuili@bnu.edu.cn (C.H. Li),

yanpeng.cai@bnu.edu.cn (Y. P. Cai).
}

ISSN: $1726-2135$ print/1684-8799 online

(C) 2018 ISEIS All rights reserved. doi: 10.3808/jei.201800387 ants would easily decrease their self-purification capacities (Nakhaei and Etemad-Shahidi, 2012). Because a river has a unique self-purification capacity, it is necessary to simulate the pollutant loads from different sources that rivers could withstand. A number of computer-aided models are thus developed and applied to predict the water quality of rivers and to simulate the fate and transport of pollutants ( Li et al., 2009, 2011; Fan et al., 2011, 2015). Over the past decades, many models have been considered suitable for water quality simulation and evaluation of the associated risks. They could thus be used to support the formulation of future water management options and the generation of national and local water pollutant discharge standards.

Previously, many models have been proposed to address the fate and transport of water pollutants in rivers, such as WASP (Water Quality Analysis Simulation Program), EFDC (Environmental Fluid Dynamics Code), and HEC-RAS (Hydrologic Engineering Center's River Analysis System). These tools have been widely used by many researchers to develop efficient management strategies to guarantee an adequate supply of high-quality water (Cox, 2003). However, these complex models may not be useful models as several limitations are associated with these models (Lindenschmidt, 2006). In particular, estimation, calibration, and validation of relevant 
parameters may require abundant monitoring data. Also, a number of parameters in certain complex simulation have seldom been report in the literature, meaning that there is little research to compare their accuracies (Melching and Yoon, 1996; Fan et al., 2009). The QUAL series models are useful simulation tools that have been applied extensively in water quality assessment, even in cases where there are not sufficient data for the establishment complex 2D or 3D models (Nakhaei and Etemad-Shahidi, 2012). For example, QUAL2E is a typical computer-aided model among the QUAL series models, the QUAL2Kw model is an the expanded version by Pelletier et al. (2006) based on QUAL2K, and it is the latest version of QUAL2E. The QUAL2Kw model can be used for automatic calibration and can be operated on a Windows interface. Comparatively, QUAL2K can be modified by introducing multiple VBA programs (Cho and Ha, 2010; Wang et al., 2018). As stated by many researchers, QUAL2Kw can provide a platform for simulating the water quality of rivers and streams. It can employ a genetic algorithm to facilitate the calibration of many QUAL2Kw-based models in applications for certain water bodies. A genetic algorithm is used in the model to identify the combination of parameters that results in the best fit for the application (Pelletier et al., 2006). In many research studies, QUAL2Kw have been applied to measure water environmental management strategies. Thus, it is generally conluded that the model can form the basis of water quality management (Kannel et al., 2007b; Oliveira et al., 2012). In many studies, DO, BOD, nitrogen, phosphorus and COD have been used as typical indicators to model water quality variations of streams and rivers (Kannel et al., 2007a; Camargo et al., 2010; Nakhaei and Etemad-Shahidi, 2012). The latest QUAL2Kw (i.e., QUAL2Kw version 6) was integrated with non-steady, nonuniform flow using a kinematic wave flow routing approach and has the option to use repeating diel conditions, which is similar to the early version but with either steady or non-steady flows (Department of Ecology of the State of Washington, 2017). Therefore, it is feasible to assess the water quality of a natural stream or river using QUAL2Kw.

Uncertainties in input and output data are an important aspect that should be investigated to obtain water quality simulation results with enhanced precision. Uncertainty analysis is a useful method to depict the uncertain relationships between modeling results and parameters. Normally, uncertainties in the input data of a model occur because of changes in natural conditions, measurement limitations, and data availability (de Kort and Booij, 2007; Shen et al., 2008; Dong et al., 2014). One way to address this issue is to use random variables as the input data rather than the conventional form of fixed values (Shen et al., 2008). Stratified random procedure latin hypercube sampling (LHS) is an effective method of sampling variables from their multivariate distributions (Minasny and McBratney, 2006; Manache and Melching, 2008). It can guarantee uniform samples for the marginal distribution of each single input and efficiently select input variables for computer models. Uncertainty also occurs in parameters. Many methods are available for the analysis of parameter uncertainty, including sensitivity analysis, first-order error analysis (FOEA), Bayesian, and Monte Carlo simulations (Shen et al., 2008). Markov simulation is also an efficient technique for simulating water quality uncertainty (Gallagher and Doherty, 2007). For the Willamette River of Oregon, US, this method provided similar results to other models with simulation data (Takyi and Lence, 1995). Markov simulations in the WASP model were demonstrated to be appropriate for parameter identification and uncertainty analysis of complex models of the Miyun Reservoir (Wang et al., 2006).

The Laoguanhe River is of significant importance for China's largest water diversion project (i.e., the South-to-North Water Diversion Project) since the river flowing into the Danjiangkou Reservoir is close to Taocha, which is the intake of the middle route of the water diversion project. The Danjingkou Reservoir is the source water area of the project, and the objective of the middle route is to provide drinking water to many cities and areas in north China. Therefore, the Danjiangkou Reservoir must maintain high water quality. The water quality of tributaries, especially the upstream tributaries, directly affects the water quality of the reservoir. Pollution from upstream tributaries is one of the most significant pollution sources of the Danjiangkou Reservoir. Analysis of the changes of water quality in these upstream tributaries is particularly important. Thus it is necessary to investigate water quality conditions in the Laoguanhe River and analyze their impacts on the Danjiangkou Reservoir.

In this study, comprehensive assessment of water quality risks will be undertaken to provide a basis for optimized decision-making to support water environmental protection of the Laoguanhe River. The QUAL2Kw model will be employed to simulate the water quality of the Laoguanhe River. A stochastic Markov process will be used to calibrate the model and calculate the water quality risks. Additionally, LHS will be used to improve the input flow to QUAL2Kw. Water quality risks will be analyzed based on the simulation results. The proposed method will offer fundamental knowledge with which to assess water quality, even when monitoring data are not sufficient. This will be extremely useful for providing basic knowledge for water quality assessments even when monitoring data are in-

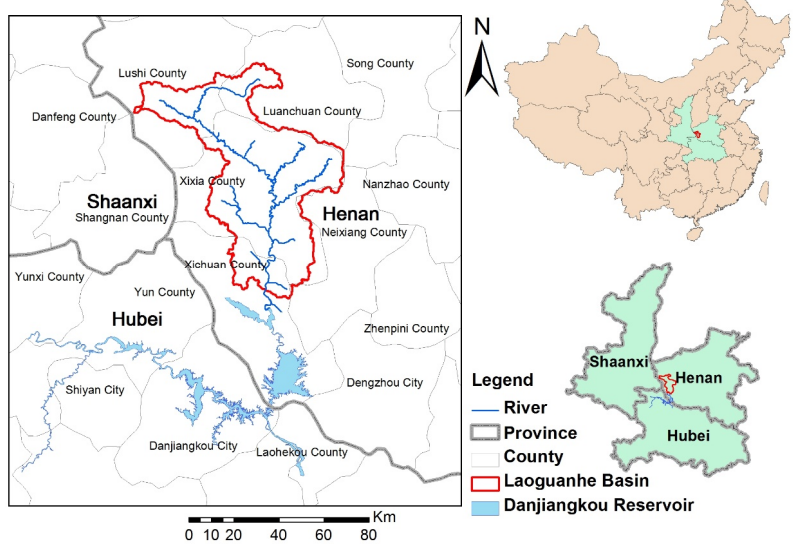

Figure 1. The Laoguanhe River and its drainage area. 
sufficient.

\section{Study Area}

\subsection{Overview of the Study Area}

The Laoguanhe River $\left(33^{\circ} 05^{\prime} \mathrm{N}\right.$ to $33^{\circ} 48^{\prime} \mathrm{N}, 111^{\circ} 01^{\prime} \mathrm{E}$ to $\left.111^{\circ} 46^{\prime} \mathrm{E}\right)$, which is located in the southwest part of Henan Province, is one of the most important upstream tributaries flowing into the Danjiangkou Reservoir. The Han River and Dan River are the two main streams of the reservoir. The Laoguanhe River originates in Luanchuan County. It flows through Lushi, Xixia and Xichuan counties. The river is approximately $254 \mathrm{~km}$ long and has a drainage area of approximately 4219 $\mathrm{km}^{2}$ (Figure 1). Mountains dominate the upstream basin of the Laoguanhe River with a mainstream length of $116 \mathrm{~km}$, which has steep banks and an approximate forest coverage index of 90\%. Below this point, the Laoguanhe River flows toward $\mathrm{Xi}-$ chuan County and runs through the Danjiangkou Reservoir. The Danjiangkou Reservoir is vital for China because it is the source water for the middle route of the South-to-North Water Diversion Project, which provides drinking water for northern China. The Water quality of the Laoguanhe River has evident impacts on the water quality of the Taocha intake of the Danjiangkou Reservoir. Therefore, it is necessary to assess the water quality risk of the Laoguanhe River.

\subsection{Water Quality of the Laoguanhe River}

Of the first-level branches of the Dan River and Han River, the Laoguanhe River is the smallest, and the distance between the Laoguanhe River and the Taocha diversion channel is the shortest. Thus, the water quality of the Laoguanhe River has a significant impact on that of the Taocha diversion channel (Chen et al., 2012; Sun et al., 2017). The Laoguanhe River has multiple tributaries, and many pollutants are directly or indirectly discharged into the river. Thus, the water quality of the Laoguanhe River is relatively poor. It is usually in level IV or $\mathrm{V}$ as evaluated by the surface water environmental quality standard of China (i.e., GB3838-2002). According to field investigations, the major source of industrial pollution into the Laoguanhe River is wastewater discharge from papermaking facilities and pharmaceutical companies. The major source of domestic pollution is household garbage, and the major agricultural pollution sources are the extensive application of pesticides and fertilizers as well as livestock and poultry farming. From this point onwards, the DO concentrations decrease and the $\mathrm{COD}$ and $\mathrm{NH}_{3}-\mathrm{N}$ concentrations rapidly increase, which shows that the water quality begins to deteriorate. The intense pollution and vital influence of the Laoguanhe River on the Danjiangkou Reservoir indicate that water quality simulations are required to prevent future deterioration of the water quality.

\section{Modeling Formulation}

\subsection{Description of QUAL2Kw}

According to the latest reports, QUAL2Kw is a modernized version of the one-dimensional water quality model QU-
AL2E and incorporates updated scientific techniques. It was developed by Tufts University and the Washington State Department of Ecology in 2006 based on the QUAL2K model (for details, please refer to www.ecy.wa.gov/programs/eap/models.html). Compared to the original QUAL2K model, QUAL$2 \mathrm{Kw}$ can simulate steady flows with repeating diel boundary conditions and with non-steady and non-uniform flows through kinematic wave flow routing. It also has an improved genetic algorithm GA-based auto-calibration module to maximize the adjustment of the simulated results based on limited fieldmeasured data. QUAL2Kw is a multipurpose model for simulating water quality in rivers and streams and is widely used in North America, Asia and Europe. It can effectively simulate the transport, migration and transformation processes of many constituents (i.e., BOD, DO, $\mathrm{NH}_{3}-\mathrm{N}$, and $\mathrm{pH}$ ) (Pelletier et al., 2006). When using QUAL2Kw, the river must be divided into several complete reaches. Each reach is considered a research unit, and the hydrological and water quality conditions in a unit are assumed to be homogeneous.

For all variables except the bottom algae, the general mass balance for a constituent $(C)$ in an element (i) (Figure 2) can be presented as (Pelletier et al., 2006):

$$
\begin{aligned}
\frac{d c_{i}}{d t}= & \frac{Q_{i-1}}{V_{i}} c_{i-1}-\frac{Q_{i}}{V_{i}} c_{i}-\frac{Q_{o u t, i}}{V_{i}} c_{i}+\frac{E_{i-1}^{\prime}}{V_{i}}\left(c_{i-1}-c_{i}\right) \\
& +\frac{E_{i}^{\prime}}{V_{i}}\left(c_{i+1}-c_{i}\right)+\frac{W_{i}}{V_{i}}+S_{i}
\end{aligned}
$$

where $Q_{i}$ and $Q_{o u t, i}$ are the flow and abstraction flow in reach, respectively, $i(\mathrm{~L} / \mathrm{d}), W_{i}$ is the external load of the constituent on reach $i(\mathrm{mg} / \mathrm{d}), V_{i}$ is the volume of reach $i(\mathrm{~L}), S_{i}$ represents the sources and sinks of the constituent because of their reactions and mass transfer mechanisms $(\mathrm{mg} / \mathrm{L} / \mathrm{d}), E_{i}$ is the bulk dispersion coefficient between the reaches (L/d), $E_{i-1}$ and $E_{i}$ are the bulk dispersion coefficients between reaches $i-1$ and $i$ and $i+1$ $(\mathrm{L} / \mathrm{d}), c_{i}$ is the concentration of the water quality constituent in reach $i(\mathrm{mg} / \mathrm{L})$, and $t$ is the time (day).

The QUAL2Kw model consists of multiple complex differential equations; it is thus difficult to locate an analytical solution. The model uses a finite difference method to identify numerical solutions. Users can solve it based on the Euler method, the Runge-Kutta method or the adaptive step algorithm according to the required calculation accuracy. Additionally, the QUAL2Kw model is complex because it includes numerous parameters and the correlation relations. Therefore, GA, an automatic global calibration method, is used. The model uses GA to maximize the goodness-of-fit of the simulated results to the observed data. A detailed description of the automatic calibration method can be found in Pelletier et al. (2006).

\subsection{Model Calibration and Validation}

3.2.1. Improvement of the goodness-of-fit objective function for calibration

The method of comparing two evaluation errors between observed and simulated data is important in calibrating the pa- 


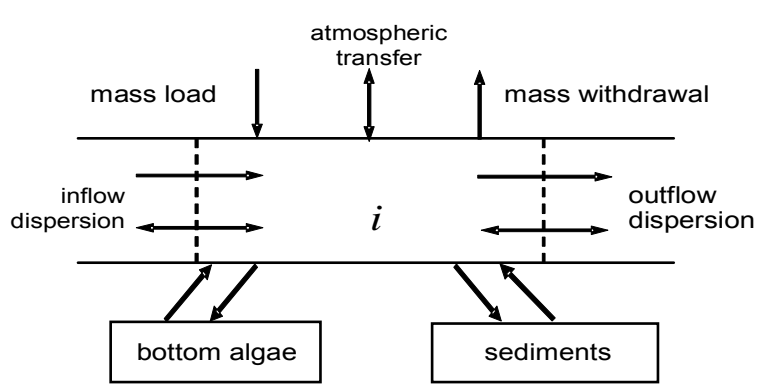

Figure 2. Mass balance in reach segment $i$.

rameters of water quality models (Harmel and Smith, 2007). To determine whether the accuracy of the water quality model can satisfy the demands of the simulated data, model calibration often uses a pairwise comparison method to evaluate the error between the observed and simulated values (Harmel and Smith, 2007; Cho and Ha, 2010). Many goodness-of-fit objective functions use the absolute error or squared error to represent the difference between the observed values and simulation values. Commonly used goodness-of-fit objective functions in water quality models include the Nash-Sutcliffe efficiency coefficient, the root mean square error (RMSE), the mean absolute error (MAE), and the index of consistency (IC). Because the RSME method is superior in the goodness-of-fit test (Legates and McCabe, 1999; Harmel and Smith, 2007), the objective function of the multi-objective genetic algorithm parameter calibration of QUAL2Kw is built based on the RMSE method to make the calibration suitable for the local char-

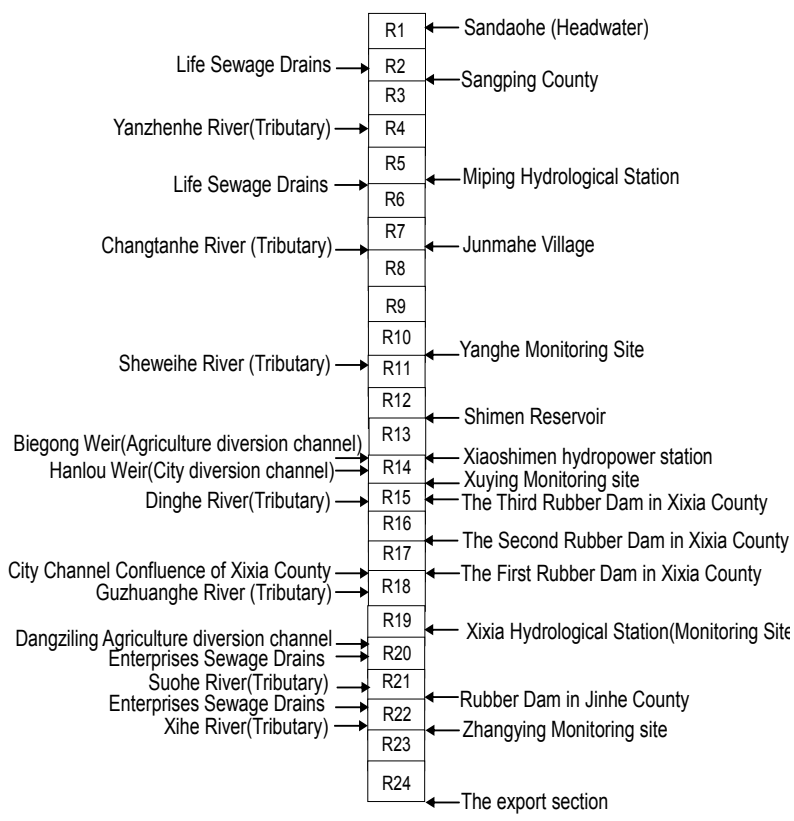

Figure 3. System segmentation with locations of pollution sources along the Laoguanhe River acteristics.

The Laoguanhe River is located in an undeveloped area. Raw data are extremely limited. In this research, the Sandaohe site was used as the headwater. During each wet season, water quality exhibits small-scale fluctuation. After manual calibration, we use a goodness-of-fit objective function to improve the calibration performance. We calculate the average of the errors between the maximum observed data and the maximum simulated data as well as the average of the errors between the minimum observed data and the minimum simulated data. The general RMSE method optimizes only a single kinetic parameter, and thus, multiple parameters must be weighted with some method, such as the principal component analysis (PCA) method according to the main water quality targets. Because of the GA method maximizes the goodness-of-fit objective function during calibration, regular RSME cannot meet the requirements of GA when establishing the objective function.

Based on the actual case of constructing the water quality model for the Laoguanhe River, the improved GA was used to maximize the goodness-of-fit objective function $f(x)$ as:

$$
\begin{aligned}
& f(x)=\sum_{i=1}^{n} w_{i} \times \sum_{i=1}^{n} 1 / w_{i} \times\left[\left(\sum_{j=1}^{m} o_{i j, \max } / m_{\text {fax }}\right)+\left(\sum_{j=1}^{m} o_{i j, \text { min }} / m_{\text {min }}\right)\right] \\
& \left./\left(\sum_{j=1}^{m}\left(p_{i j, \text { max }}-O_{i j, \text { max }}\right)^{2} / m_{\max }\right)^{1 / 2}+\left(\sum_{j=1}^{m}\left(p_{i j, \text { min }}-O_{i j, \text { min }}\right)^{2} / m_{\min }\right)^{1 / 2}\right]
\end{aligned}
$$

where $o_{i j, \max }$ is the maximum measured (observed) data; $p_{i j, \max }$ is the maximum modeled (predicted) data; $m_{\max }$ is the number of maximum measured points; $o_{i j, \min }$ is the minimum measured (observed) data; $p_{i j, \text { min }}$ is the minimum modeled (predicted) data; $m_{\min }$ is the number of minimum measured points; $w_{i}$ is the weight; and $n$ is the number of water quality objects.

\subsubsection{Generalization of River Reaches}

Generalizing a river channel based on hydrodynamic and water quality characteristics is required to build a water quality model. To generalize, the river channel should first be divided into different reaches. These processes will help the water quality model to calculate the results.

Because of the lack of statistical data and water quality monitoring data in the upstream section of the Laoguanhe River, where there are limited human impacts and lower likelihood of water pollution, we use the Sandaohe water quality monitoring site, which is the most upstream water quality monitoring site, as the source of the Laoguanhe River to develop the water quality model. This research divides the river into 24 reaches (Figure 3), models the tributaries as point sources that input into the river model, and considers sewage as diffuse sources of pollution. Xixia County transfers water from the Hanlou weir into the city river (R14), and mixed urban sewage wastewater is discharged into the Laoguanhe River from R18. Two agricultural irrigation facilities are located 
along the Laoguanhe River: the Biegong weir at R14 and the Dangziling irrigation diversion canal at R20. Four rubber dams are located along the river, including three dams in Xixia County (R15 R18) and one located downstream of the Jinhe Bridge in Xichuan County (R21). As reported, R11 R12 include a channel-type reservoir called the Shimen Reservoir. Because the reservoir has no diversion effect and is mainly used for storing water, it is set as a weir in the computation.

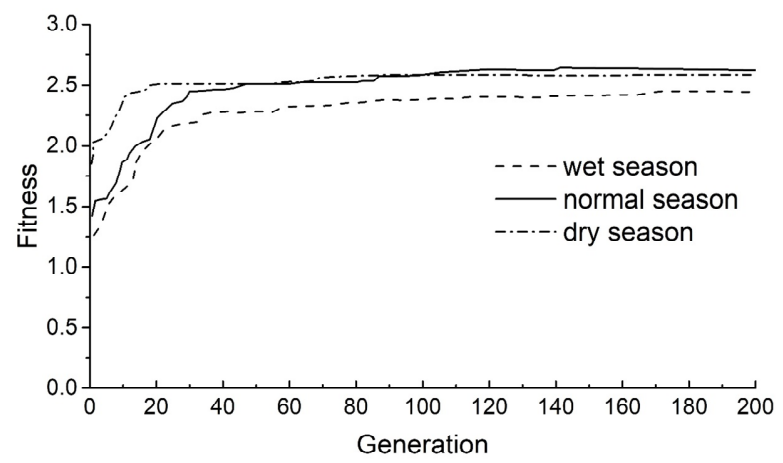

Figure 4. Goodness-of-fit of the QUAL2Kw model calibration of the Laoguanhe River.

\subsubsection{Model Calibration}

Due to the water temperature, sunshine, riverbed vegetation, and other differences among the three seasons (Table 1), the final calibration result is further optimized depending on the circumstances of the differences for every season after the manual calibration. We improved the calibration results using the improved genetic algorithm method. We assumed that the population of the model was 100, and 200 generations were used in the evolution. Small variability was realized after 100 generations as shown in the goodness-of-fit curves (Figure 4), which demonstrated that the calibration is convergent. The normal season had the highest fitness, followed by the dry season and wet season, successively. The last parameters in the model are preserved as the final parameter calibration results (Table 2). The wet season, dry season and normal season used August, February and April water quality monitoring data from
2012, respectively, for calibration. Figure 5 shows the calibration results of the $\mathrm{NH}_{3}-\mathrm{N}, \mathrm{COD}$ and DO concentrations. The DO concentration had the largest deviation.

\subsubsection{Model Validation}

Observed data from June, July and September were used for the $\mathrm{NH}_{3}-\mathrm{N}, \mathrm{COD}$ and $\mathrm{DO}$ validations during the wet season (Figure 6(a)). The data from January and March were used for model validation in the dry season (Figure 6(b)), and data from May, October and November were used for the normal season model validation (Figure 6(c)). The fits of the data in the dry and normal seasons are better than that of the wet season because of the worse water quality during the wet season. The fits of $\mathrm{DO}$ and $\mathrm{NH}_{3}-\mathrm{N}$ are better than that of COD during the wet and normal seasons, and the fits of $\mathrm{NH}_{3}-\mathrm{N}$ and $\mathrm{COD}$ are better than that of DO during the dry season. The relative errors of the validation were between 0.01 and 0.5 for every month of the wet season, and the relative errors during the dry season were between 0.02 and 0.27 , except for COD and $\mathrm{DO}$ at the Yanghe monitoring site (the simulated COD values were much higher, and the simulated DO values were much lower). The results indicate that the validation results of the dry season were much better than those of the wet season. The validation results of the normal season show that the simulated results match the variations in water quality. In addition, the validations at a distance from 10 to $80 \mathrm{~km}$ had larger errors. The simulated $\mathrm{NH}_{3}-\mathrm{N}$ and $\mathrm{COD}$ values are high. The simulated DO values are significantly low. The Laoguanhe River is located in an underdeveloped area of China, and the monitoring capacity is limited; the distance from 10 to $80 \mathrm{~km}$ has only one monitor site (i.e., Yanghe Monitoring Site). The section of the Laoguanhe River flows across Sangping village, Miping village, Junmahe Village and Xixia County. The most domestic sewage of these areas discharges into the city river or directly discharges to the Laoguanhe River. A number of factories and farms are located near the Laoguanhe River. With the process of urbanization and industrialization, and pollutant discharge fluctuates daily, the uncertainty of the simulation accuracy increases. Overall, excluding the impact of the simulation errors at some monitoring sites, QUAL2Kw can accurately simulate the variations of water quality in the Laoguanhe River.

Table 1. Division of Water Seasons for the Laoguanhe River

\begin{tabular}{|c|c|c|c|c|c|c|c|c|c|c|c|c|}
\hline Water season & & $\mathrm{We}$ & ason & & Dry season & & & & al seas & & & \\
\hline Month & Jun. & Jul. & Aug. & Sep. & Jan. & Feb. & Mar. & Oct. & Nov. & Dec. & Apr. & May \\
\hline
\end{tabular}

Table 2. Calibration Results of the Water Quality of the Laoguanhe River Using the QUAL2Kw Model

\begin{tabular}{llllll}
\hline Parameter & Unit & Symbol & Wet season & Dry season & Normal season \\
\hline Sedimentation rate & $\mathrm{m} / \mathrm{d}$ & $\mathrm{vi}$ & 0.637 & 0.666 & 0.634 \\
Hydrolysis rate of organic nitrogen & $/ \mathrm{d}$ & $\mathrm{khn}$ & 3.316 & 4.247 & 3.619 \\
Sedimentation rate of organic nitrogen & $\mathrm{m} / \mathrm{d}$ & $\mathrm{von}$ & 0.808 & 0.987 & 1.982 \\
Nitrification rate & $/ \mathrm{d}$ & $\mathrm{kna}$ & 9.964 & 9.587 & 9.490 \\
Denitrification rate & $/ \mathrm{d}$ & $\mathrm{kdn}$ & 0.410 & 0.754 & 0.838 \\
Denitrification rate of humus & $\mathrm{m} / \mathrm{d}$ & $\mathrm{vdi}$ & 0.456 & 0.044 & 0.526 \\
Oxidation rate of COD & $/ \mathrm{d}$ & $\mathrm{kgen}$ & 1.090 & 1.088 & 1.626 \\
Sedimentation rate of COD & $\mathrm{m} / \mathrm{d}$ & $\mathrm{vgen}$ & 0.133 & 0.634 & 0.229 \\
\hline
\end{tabular}




\subsection{Sensitivity Analysis}

The parameter sensitivity analysis based on the calibration results of the GA is shown in Figures 7(a) through 7(f). During the wet season, there are negative correlations between the denitrification rate, the sedimentation rate of COD, and the denitrification rate of humus. The other parameters have positive correlations. In addition, the variance contribution rates of the goodness-of-fit with the denitrification rate, hydrolysis rate of organic nitrogen, nitrification rate and sedimentation rate of COD are larger than the others. During the dry season, there are positive correlations between the hydrolysis rate of organic nitrogen, the sedimentation rate of COD, and the sedimentation rate of organic nitrogen. The variance contribution rate of the goodness-of-fit with the COD oxidetion rate is the largest at $35 \%$, followed by the sedimentation rate, which is greater than $20 \%$. During the normal season, there are positive relationships between the sedimentation rate of organic nitrogen, the sedimentation rate, and the nitrifycation rate. The other parameters have negative relationships. The variance contribution rate of the goodness-of-fit with the sedimentation rate of organic nitrogen is $30 \%$, and the oxidetion rate of COD and sedimentation rate of COD are both greater than $20 \%$.

\section{Water Quality Risk Assessment under Uncertainty}

Flow is one of the most important boundary conditions for the water quality numerical model. The flow data of the Laoguanhe River are limited and discontinuous. Therefore, we use latin hypercube sampling to improve the flow input and analyze the water quality uncertainty of the basis hydrological year (Fan et al., 2017a, b; Helton and Davis, 2003). We then use Markov transfer analysis to calculate the flow probability distribution and use the LHS method to analyze the water quality uncertainty of different hydrological years. Furthermore, we use this method to analyze the water quality uncertainty among differrent scenarios. The major steps of the water quality risk simulation are shown in a flowchart in Figure 8. LHS is a stratified random procedure that provides an efficient way to sample variables from their multivariate distributions (Mi-

nasny and McBratney, 2006). It can guarantee uniform samples for the marginal distribution of each input and efficiently select input variables for computer models. The Markov process was proposed by the Russian mathematician A. A. Markov in 1907. It is a stochastic process that assumes that in a series of random events, the probability of the occurence of each event depends only on the immediately preceding outcome (Maity, 2012). This indicates that the prediction based on the present information and that based on knowing all of the historic information are equivalent.

A Markov process can be described as a sequence of uncertainty decision-making processes. At every moment, the system state provides necessary the information necessary to select actions for decision-making in the form of the transition probabilities. Random variables $Q$, which are denoted $\left(Q_{n}=\right.$ $Q(n), n=0,1, \ldots$,$) , are homogeneous with respect to time t$ with the state space $I=\left(a_{1}, a_{2}, \ldots, a_{i}\right)$ of a first-order Markov process. The transfer matrix $P=\left(p_{i j}\right)$ is defined below, where $p_{i j}=P_{i j}(1)=P\left\{X_{m}+1=a_{j} \mid X_{m}=a_{i}\right\}$.

$P=\left[\begin{array}{cccc}p_{11} & p_{12} & \cdots & p_{1 j} \\ p_{21} & p_{22} & \cdots & p_{2 j} \\ \vdots & \vdots & \ddots & \vdots \\ p_{1 i} & p_{21} & \cdots & p_{i j}\end{array}\right]$

where $p_{i j}=n_{i j} / n_{i}$ represents the probability that the state $a_{i}$ transfers to $a_{j}$ from time $n$ to $n+1 ; n_{i j}$ is the number of samples in which the state $a_{i}$ transfers to $a_{j}$ from time $n$ to $n+1$; and $n_{i}$ is the number of samples at time $n$ with the state $a_{i}$. In this study, we first used the water balance equation to transfer the flow data from the Miping hydrological station to the Sandaohe monitoring point, which is the source in this model. We then constructed the first-order Markov process for the Laoguanhe River's flow, where the results are only affected by the last out-

Table 3. Surface Water Quality Evaluation Standard (mg/L)

\begin{tabular}{cccccc}
\hline Indicator & I & II & III & IV & V \\
\hline $\mathrm{NH}_{3}-\mathrm{N}$ & 0.15 & 0.5 & 1 & 1.5 & 2 \\
$\mathrm{DO}$ & 7.5 & 6 & 5 & 3 & 2 \\
$\mathrm{COD}$ & 15 & 15 & 20 & 30 & 40 \\
\hline
\end{tabular}
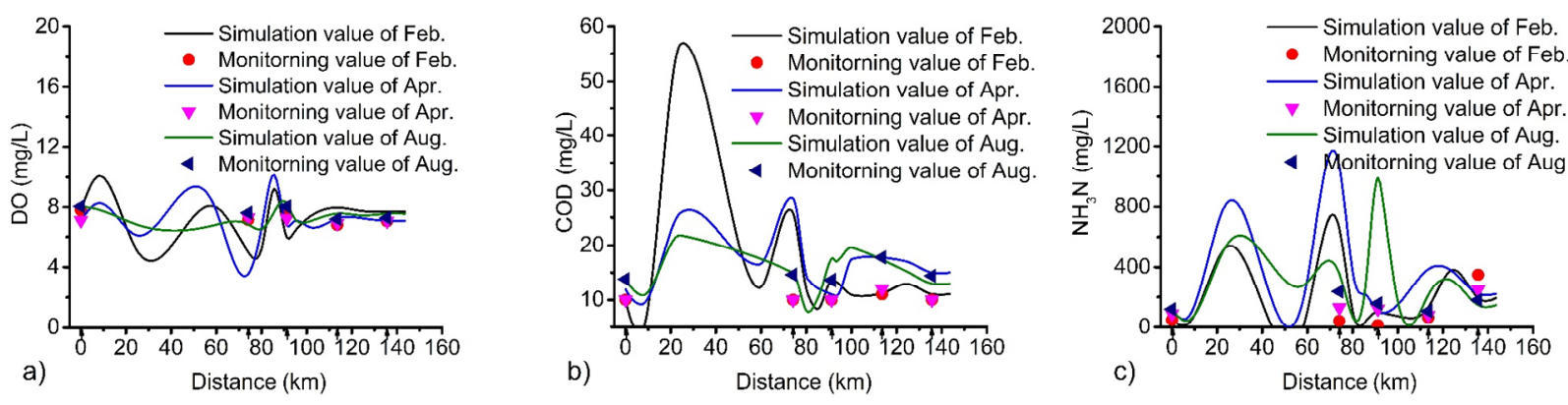

Figure 5. Calibration results of the model. a) the results of DO; b) the results of COD; c) the results of $\mathrm{NH}_{3}-\mathrm{N}$. The five arrows in lateral axis from left to right stand for Sandaohe, Yanghe, Xuying, Xixia, Zhangying monitoring sites respectively. 

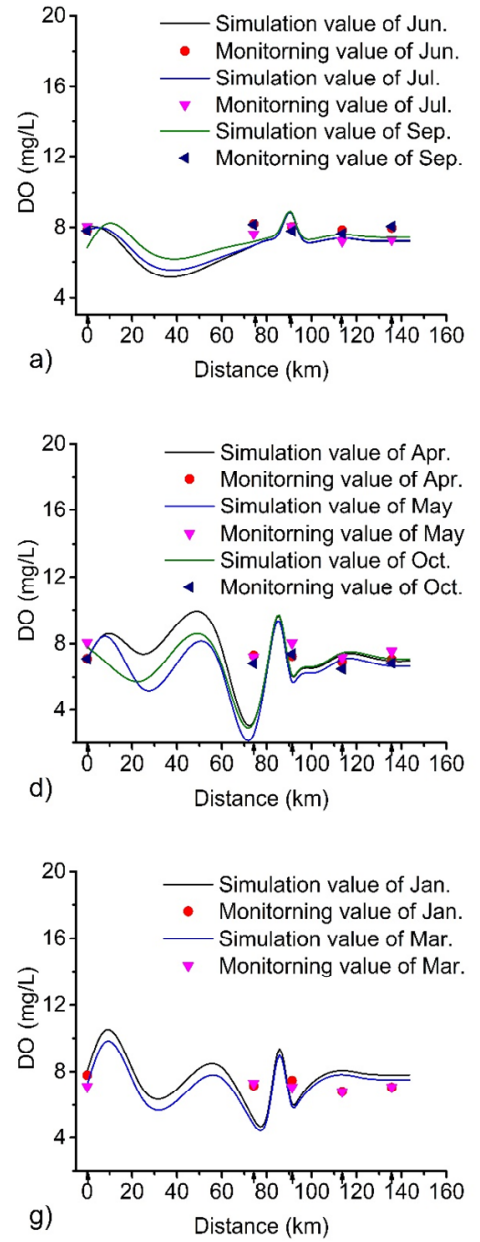
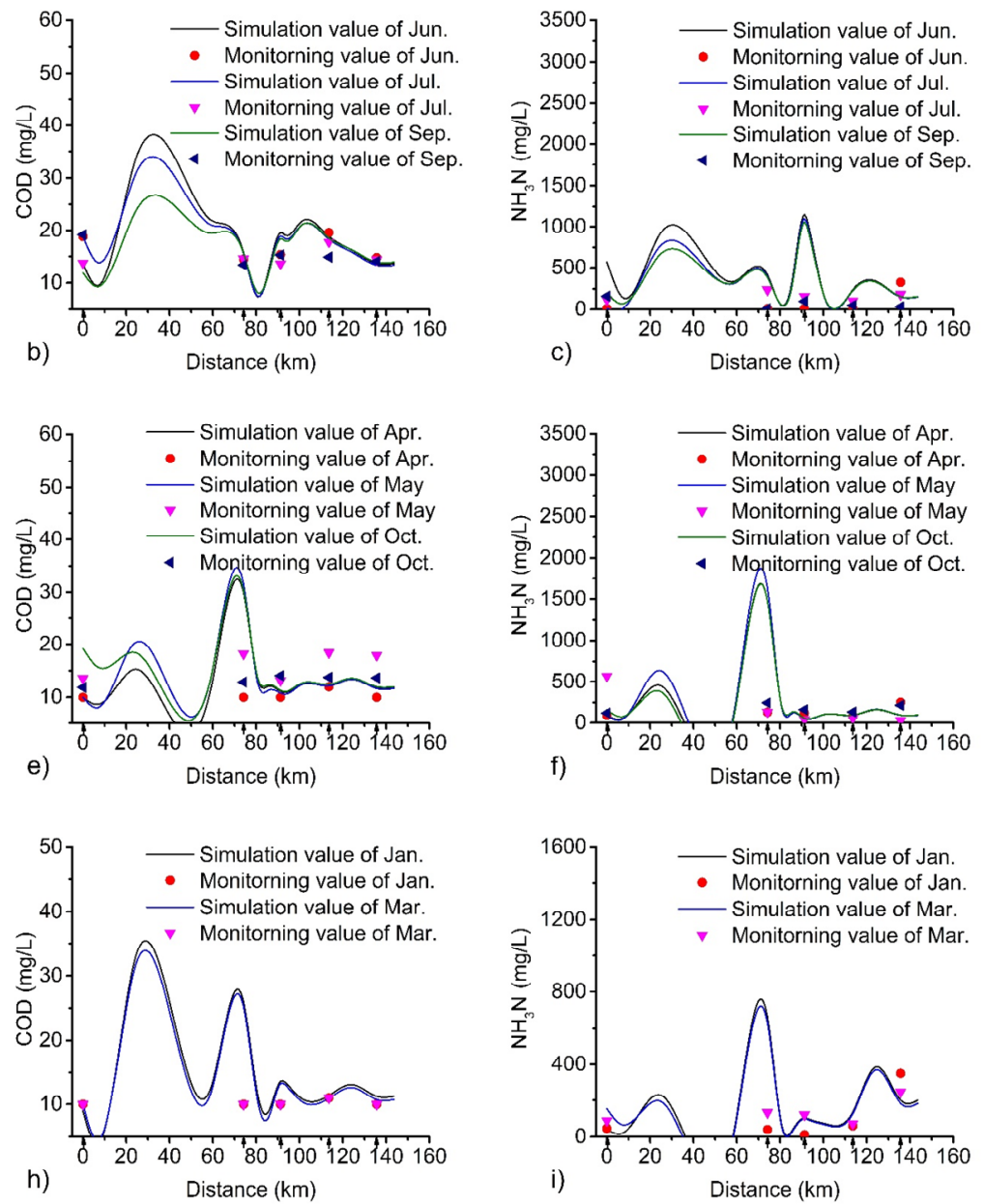

Figure 6. Validation results of the model. a) $\sim$ c) are the results of wet seasons; d) $\sim$ f) are the results of normal seasons; g) $\sim$ i) are the results of dry seasons. The five arrows in lateral axis from left to right stand for Sandaohe, Yanghe, Xuying, Xixia,

Zhangying monitoring sites respectively.

put. Specific steps of monthly flow data generation are shown in Figure 9.

(1) Average daily flow data from 2007 2012 were used to establish the cumulative frequency distribution of the flow. The distribution was divided into 10 state spaces with a $10 \%$ guarantee rate interval, i.e., $Q=\left\{Q_{90}, Q_{80}, Q_{70}, Q_{60}, Q_{50}, Q_{40}\right.$, $\left.Q_{30}, Q_{20}, Q_{10}, Q_{0}\right\}$, where $Q 0$ is the 0 to $10 \%$ guaranteed rate of flow, $Q_{10}$ is the 10 to $20 \%$ guaranteed rate of flow, $Q_{20}$ is the 20 to $30 \%$ rate of flow, and so on, with $Q_{90}$ as the 90 to $100 \%$ guaranteed rate of flow. (2) To ensure normal operation of the modeling calculations, we divide the flow data from each month into 3 equal portions with equal intervals. Then, the arithmetic mean of each portion was calculated as the initial average daily flow for each month to establish the first-order Markov transition matrix of the flow. (3) The flow data were obtained to generate cumulative distributions of the flow for different hydrological years. Then, latin hypercube sampling was used to extract the flow data from the cumulative distribution into the first-order Markov transition matrix. The cumulative frequency distribution of the flow that was constructed in step (1) was used to interpolate and generate the flow data of the next month. (4) The newly generated flow data was used as the random variation boundary conditions for QUAL2Kw to calculate the water quality of each month. Finally, the results of the water quality simulation were adopted to calculate the risk probability.

\section{Results and Discussion}

\subsection{Water Quality Simulation}

The pollutant emission scenarios are generated from a survey of pollutant sources in the Laoguanhe River. The year 2012 is assumed as the basis hydrological year and is used to simulate the water quality based on the uncertainty using the LHS sampling method. The average water qualities for different hydrological periods are set as the initial water quality for the simulations, and we obtain the probability distribution of water quality for each month. 
With the increasing frequency of extreme climates, drought and flood frequently occur in China. Under this consideration, we set three guaranteed flow rate scenarios for different hydrological years. Based on the cumulative distribution of flow for every January from 2006 to 2012, the initial month's flow in a flood year is based on the 0 to $25 \%$ guaranteed flow rate and that for a dry year is based on the 75 to $100 \%$ guaranteed flow rate, and that for a level year is based on the 25 to $50 \%$ guaranteed flow rate. These data were applied to simulate water quality for the entire year. The water quality probability distributions of the wet season, dry season and normal season in each year can then be simulated. The water quality evaluation is based on the surface water quality environment standard of China (GB3838-2002) (Table 3); the water quality needs to meet the level-II standard.

\subsubsection{Risk of a Basis Hydrological Year}

For QUAL2Kw, the average daily flow data from January to November 2012 are the most important inputs. The flow data are used for LHS sampling. The monitoring data for every month are used as the initial boundary conditions of water quality. The results of the water quality model are adopted to calculate the water quality risk probability and analyze the environmental risk (Figure 10, and the complete results can be referred to Table S1 in supplementary information).

The results show that the simulated water qualities at the Xuying, Xixia, and Zhangying monitoring sites in the basis year meet the water quality targets and that the water that is exported from the Laoguanhe River to the Danjiangkou Reservoir meets the level-II standard. The water quality analysis
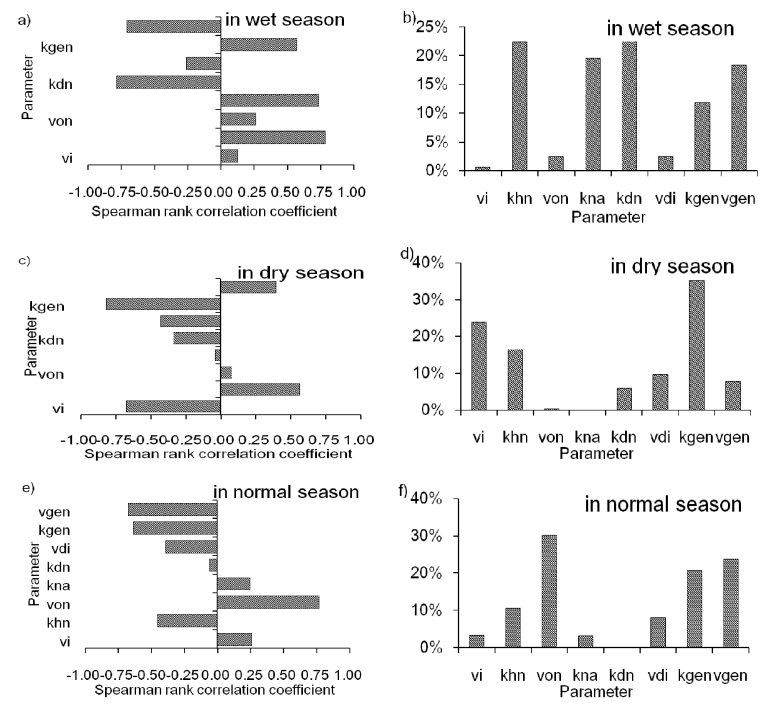

Figure 7. Parameter sensitivity analysis. a) parameter sensitivity analysis result in wet season; b) variance contribution rates of the parameters in wet season; c) parameter sensitivity analysis result in dry season; d) variance contribution rates of the parameters in dry season; e) parameter sensitivity analysis result in normal season; f) variance contribution rates of the parameters in normal season.

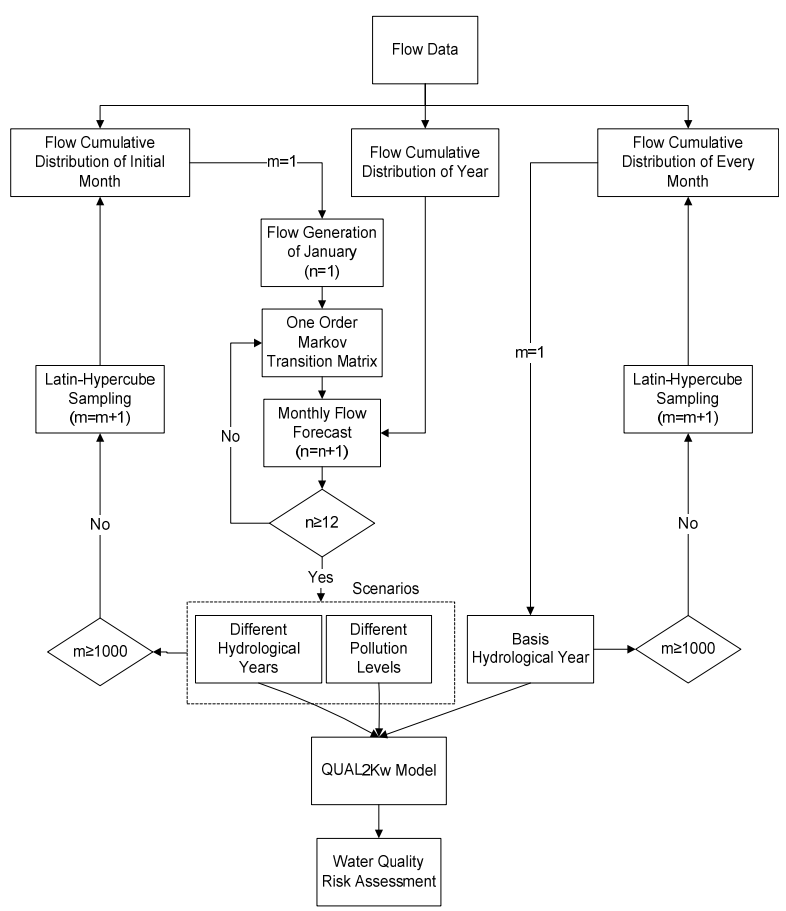

Figure 8. Water quality risk assessment flowchart.

of each season shows the following. (1) The dry season occurs in January, February, and March. The general trends of the water quality of each month during the dry season were similar, and the concentration of pollution decreases gradually during this season. The $\mathrm{NH}_{3}-\mathrm{N}$ concentration was highest at the Zhangying site, with values between 0.30 and $0.43 \mathrm{mg} / \mathrm{L}$, and generally remained at the level-II surface water quality standard. The DO concentration decreases every month, especially at the Xixia hydrological station; the probability of DO non-compliance is $65 \%$. (2) The normal season occurs in April and May and again in October and November. DO concentrations that exceed the standard are the main threat to water quality during the normal season. The probability of DO non-compliance at the Xixia hydrological station is 58\% in April and nearly $100 \%$ in May. The concentration of COD at the Xixia hydrological station was also higher than at the other sites, and the probability of non-compliance in November is nearly $100 \%$. The concentration of $\mathrm{NH}_{3}-\mathrm{N}$ at the Zhangying monitoring site is highest but still remained within the level-II standard. (3) The wet season occurs from June to September. During the wet season, the water quality was mainly threatened by COD. Agriculture is one of the most important industries in the Laoguanhe River basin, and these areas have limited domestic sewage treatment facilities; during the wet season, the domestic sewage and chemical fertilizer have more opportunity to be rushed into the Laoguanhe River, which would increase the risk of noncompliance. The concentrations of COD at the Zhangying monitoring site were between 14.9 and $17.5 \mathrm{mg} / \mathrm{L}$, and the risk of non-compliance was $96 \%$ in June and $89 \%$ in September. The concentrations of COD at the Xuying monitoring site and $\mathrm{Xi}$ xia hydrological station were also relatively high; the average concentrations were 13.15 and $13.49 \mathrm{mg} / \mathrm{L}$, respectively. The 


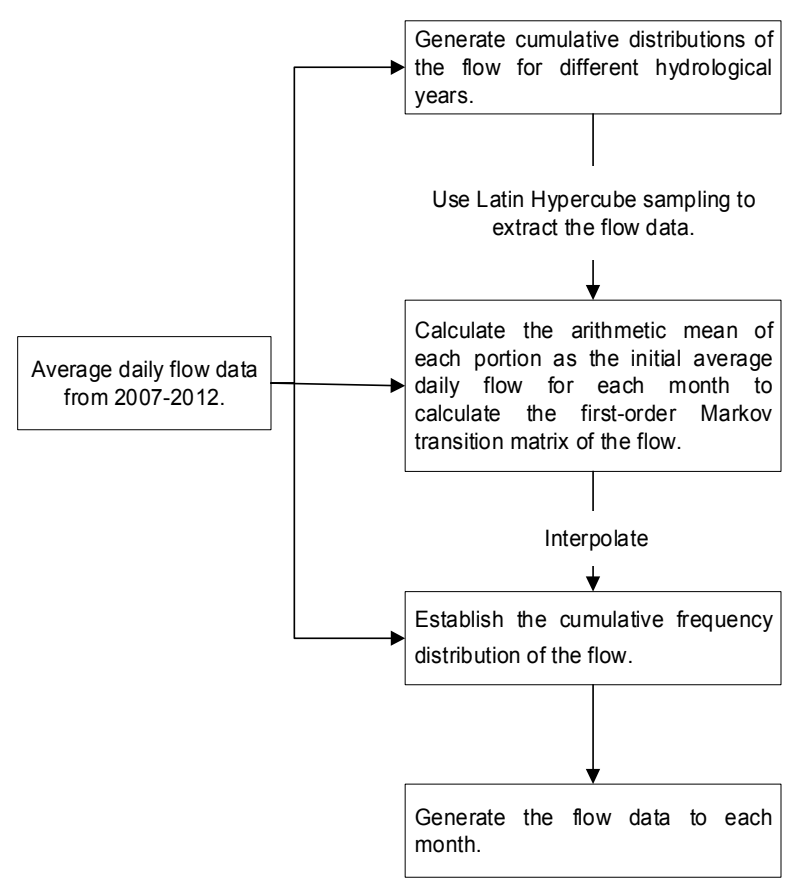

Figure 9. Monthly flow data generation flowchart.

overall trends in July and August were the same as in June, and there was some improvement. The probability of the COD concentration exceeding the standard at the Zhangying monitoring site decreased to 19 and $37 \%$. However, in September, the water quality decreased, and the probability of the COD concentration exceeding the standard increased to $89 \%$. At the same time, the probability at the Xixia hydrological station was $14 \%$.

Thus, during the dry season, the Xixia hydrological station had a relatively high probability of exceeding the standards. During the normal season, the main threat was from DO exceeding the water quality standards at the Xixia hydrological station, and during the wet season, the water at the Zhangying monitoring site threatened to not meet the standards.

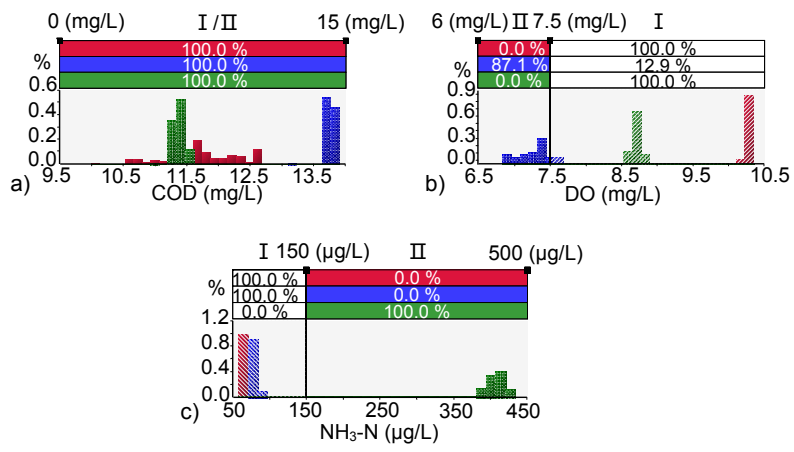

Figure 10. Simulation results for the basis hydrological year (set $\mathrm{NH}_{3}-\mathrm{N}$ Jan. as examples). a) the results of COD; b) the results of DO; c) the results of $\mathrm{NH}_{3} \mathrm{~N}$. The red, blue and green represent Xuying, Xixia, Zhangying monitoring sites respectively.
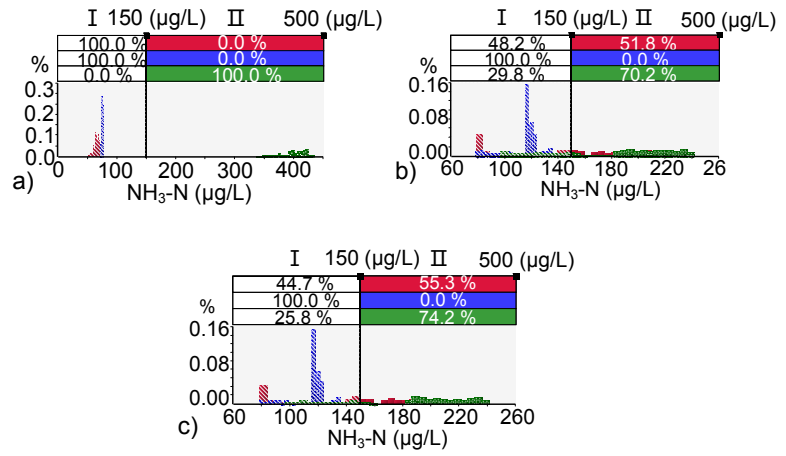

Figure 11. Simulation results in different hydrological years (set $\mathrm{NH}_{3}-\mathrm{N}$ in wet season as examples). a) the results of level year; b) the results of dry year; c) the results of flood year. The red, blue and green represent Xuying, Xixia, Zhangying monitoring sites respectively.

Although the simulation results at the Zhangying monitoring site did not show substandard water, it is the nearest monitoring site to the Danjiangkou Reservoir, so it still poses some level of threat.

\subsubsection{Risk of Multiple Hydrological Years}

In this study, we use the P-III frequency analysis and the average distance percentage as the division runoff of wet year, normal year and dry year. The annual runoffs were calculated from 2007 to 2012 and showed that 2010 and 2011 were wet years, 2007 and 2009 were normal years, and 2008 and 2012 were dry years. We used the average daily flow data from January 2010 and 2011 to construct the cumulative probability distribution to be used as the sampling distribution for the wet years, the average daily flow data from January 2007 and 2009 to construct the cumulative probability distribution for the normal years, and the average daily flow data from January 2008 and 2012 to construct the cumulative probability distribution for the dry years. We then calculated the water quality risk for wet years, normal years and dry years. The average monitoring data for every season in 2012 were used as the initial water quality boundary conditions. The cumulative distributions of flow for the wet year, dry year and normal year can be calculated by Markov transfer analysis, and the water quality probability distributions of the different hydrological years can be simulated using the LHS sampling method. The results are shown in Figure 11 (the complete results can be referred to Table S2 in supplementary information). The water quality analysis of each season shows the following:

(1) The simulation results for the wet year showed that the $\mathrm{NH}_{3}-\mathrm{N}$ can meet the class-II standard consisting of concentration that is lower than $0.5 \mathrm{mg} / \mathrm{L}$. In addition, the $\mathrm{NH}_{3}-\mathrm{N}$ concentration at the Zhangying monitoring site was higher than the concentration at the Xixia hydrological station and the $\mathrm{Xu}-$ ying monitoring site. The DO at the Xuying and Zhangying monitoring sites can meet the class-II standard consisting of the concentration that is higher than $6 \mathrm{mg} / \mathrm{L}$, especially during the 

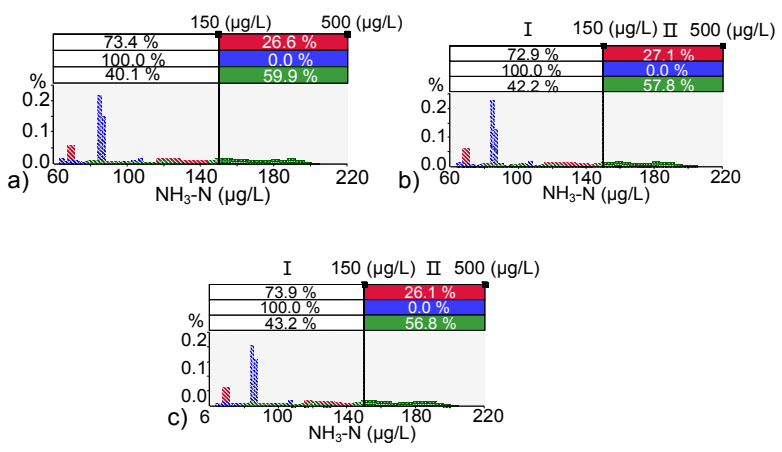

Figure 12. Results for a $20 \%$ decrease of pollutants in different hydrological years (set $\mathrm{NH}_{3}-\mathrm{N}$ in wet season as examples). a) the results of level year; b) the results of dry year; c) the results of flood year. The red, blue and green represent Xuying, Xixia, Zhangying monitoring sites respectively.

dry season and normal season, when it can meet the class-I standard; however, the probability of DO non-compliance at the Xixia hydrological station was $0.8 \%$ during the dry season and $8.2 \%$ during the normal season. The COD at the Xuying monitoring site and the Xixia hydrological station can meet the class-II standard; however, the Zhangying monitoring site, which is the closest monitoring site to the Danjiangkou Reservoir, had a probability of COD non-compliance of approximately $26.5 \%$ during the wet season.

(2) During the dry year, the water quality was poor at the Zhangying monitoring site and Xixia hydrological station. The probability of COD non-compliance was $25.1 \%$ at the Zhangying monitoring site during the wet season. At the Xixia hydrological station, the probability of DO exceeding the standard during the dry season and the normal season are 0.6 and $10.6 \%$, respectively. The Zhangying monitoring site has a $0.1 \%$ probability of $\mathrm{NH}_{3}-\mathrm{N}$ exceeding the standard of $500 \mu \mathrm{g} / \mathrm{L}$.

(3) During the normal year, the DO concentrations were higher than $6 \mathrm{mg} / \mathrm{L}$ at the Xixia hydrological station, except
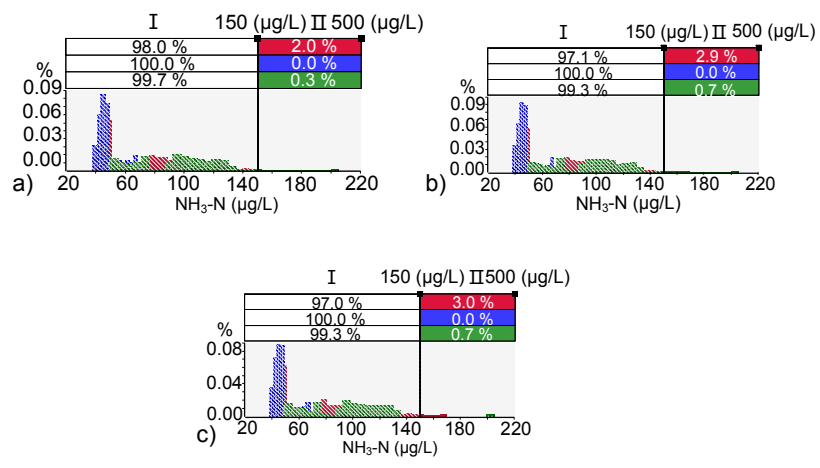

Figure 13. Results for a $50 \%$ decrease of pollutants in different hydrological years (set $\mathrm{NH}_{3}-\mathrm{N}$ in wet season as examples). a) the results of level year; b) the results of dry year; c) the re-sults of flood year. The red, blue and green represent Xuying, Xixia, Zhangying monitoring sites respectively. for during the wet season. The probabilities of DO non-compliance during the dry season and the normal season are 1.8 and $9.2 \%$, respectively. The $\mathrm{NH}_{3}-\mathrm{N}$ can meet the class-II standard because the concentrations are less than $500 \mu \mathrm{g} / \mathrm{L}$ for the entire year. The COD concentration was high during the wet season, and the probability of the concentration exceeding $15 \mathrm{mg} / \mathrm{L}$ at the Zhangying monitoring site is approximately $27.1 \%$.

\subsection{Prediction of Pollutants under Multiple Pollution Loading Conditions}

With the development of urbanization and industrialization, pollutant discharge fluctuates significantly. Different countermeasures will cause different results. In this study, water quality simulations were performed for four scenarios. We make the small decreasing, mild decreasing, small increasing and heavy increasing of pollutant emissions to present the differrent water pollution control levels. Accordingly, the scenarios considered pollutant emissions that decreased by 20 and $50 \%$ and increased by 20 and $50 \%$, respectively.

(1) Scenario 1: 20\% decrease in pollutant emissions

During a flood year, COD always meets the water quality requirement at the entry of the Laoguanhe River into the Danjiangkou Reservoir. DO is significant at the Xixia hydrological station. The probability of DO non-compliance is $0.3 \%$ during the dry season and 5.2\% during the normal season at the Xixia hydrological station, and the Zhangying monitoring site has a $0.1 \%$ probability of $\mathrm{NH}_{3}-\mathrm{N}$ exceeding $500 \mu \mathrm{g} / \mathrm{L}$ (Figure 12, Table S3). During a dry year, $\mathrm{NH}_{3}-\mathrm{N}$ and COD meet the basic requirements of water quality at the entry of the Laoguanhe River into the Danjiangkou Reservoir. The DO is significant during the dry and normal seasons. The probability of DO noncompliance is $0.2 \%$ during the dry season and $6.7 \%$ during the normal season at the Xixia hydrological station (Table S3). During a level year, the COD emissions can meet the requirements of the class-II water quality standard at the entry of the river into the Danjiangkou Reservoir. The water quality is poor during the normal season; the probability of DO non-compliance is $7 \%$ at the Xixia hydrological station, and the probability of $\mathrm{NH}_{3}-\mathrm{N}$ non-compliance is $1 \%$ at the Zhangying monitoring station (Table S3).

(2) Scenario 2: $50 \%$ decrease in pollutant emissions

When $\mathrm{NH}_{3}-\mathrm{N}$, DO and COD decrease by $50 \%$ during a flood year, they always meet the level-II standard at the entry to the Danjiangkou Reservoir (Figure 13, Table S4). During a dry year, $\mathrm{NH}_{3}-\mathrm{N}$ and $\mathrm{COD}$ meet the level-II standard at the entry to the Danjiangkou Reservoir. The DO also meets the requirement during the dry season and wet season. However, during the normal season, the probability of DO non-compliance is approximately $2.6 \%$ at the Xixia hydrological station (Table S4). The same trends occur during a level year; $\mathrm{NH}_{3}-\mathrm{N}$ and COD meet the level-II standard at the entry to the Danjiangkou Reservoir. The DO also meets the requirement during the dry season and wet season, but the Xixia hydrological station has a probability of DO non-compliance of approximately $2.4 \%$ during the normal season (Table S4). 


\section{(3) Scenario 3: 20\% increase in pollutant emissions}

When the pollution increases by $20 \%$ during a flood year, the class-II standard at the entry to the Danjiangkou Reservoir is only achieved by $\mathrm{NH}_{3}-\mathrm{N}$ and $\mathrm{COD}$ during the dry season and by $\mathrm{DO}$ and $\mathrm{NH}_{3}-\mathrm{N}$ during the wet season. During the normal season, all three pollutants have risks of non-compliance; the probability of DO non-compliance is approximately $62.9 \%$ at the Xixia hydrological station, while the probability of $\mathrm{NH}_{3}-\mathrm{N}$ non-compliance at the Zhangying monitoring site is approximately $0.1 \%$, and the probability of COD non-compliance at the Xixia hydrological station is approximately $91.9 \%$. During the wet season, the COD pollution is especially seriously; it exceeds the level-II standard at the three monitoring sites. The probability of $\mathrm{NH}_{3}-\mathrm{N}$ non-compliance is approximately $5 \%$ at the Xuying monitoring site, $68 \%$ at the Xixia hydrological station, and approximately $73.4 \%$ at the Zhangying monitoring site (Figure 14, Table S5). During a dry year, the $\mathrm{NH}_{3}-\mathrm{N}$ at the three monitoring sites meets the level-II standard at the entry to the Danjiangkou Reservoir. The DO meets the standard only during the wet season of a dry year. During the level and dry seasons, the probabilities of DO non-compliance at the Xixia hydrological station are approximately $8.9 \%$, and the probabilities of COD non-compliance at the Xixia hydrological station are both approximately $99.7 \%$. During the wet season of a dry year, the probability of DO non-compliance is approximately $11.4 \%$ at the Xuying monitoring site, approximately $69.8 \%$ at the Xixia hydrological station and approximately $75.5 \%$ at the Zhangying monitoring site (Table S5).

When $\mathrm{NH}_{3}-\mathrm{N}$ increases by $20 \%$ during a level year, the probability of non-compliance increases significantly. The $\mathrm{NH}_{3}-\mathrm{N}$ can only reach the level-II standard at the entry to the Danjiangkou Reservoir during the wet season at all three sites. During the normal season, the probability of $\mathrm{NH}_{3}-\mathrm{N}$ non-compliance is approximately $84.4 \%$ at the Xixia hydrological station, approximately $6.5 \%$ at the Xuying monitoring site, and approximately $6.5 \%$ at the Zhangying monitoring site. The DO pollution meets the requirement at the three monitoring sites during the wet season. However, the probabilities of $\mathrm{NH}_{3}-\mathrm{N}$ non-compliance
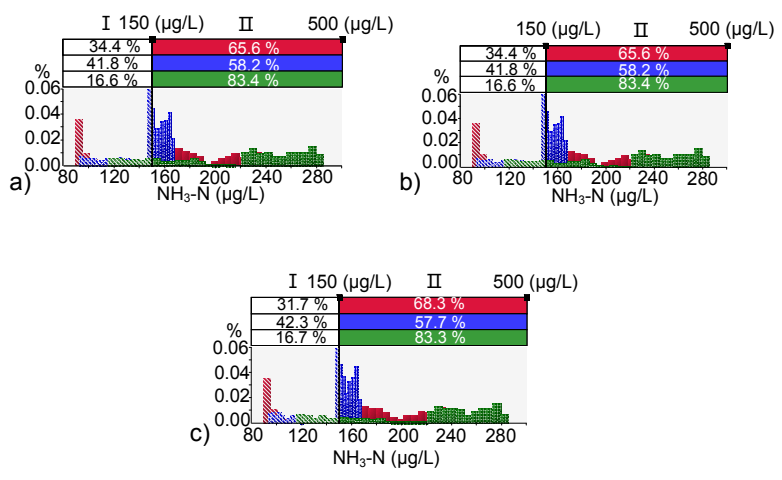

Figure 14. Results for a $20 \%$ increase of pollutants in different hydrological years (set $\mathrm{NH}_{3}-\mathrm{N}$ in wet season as examples). a) the results of level year; b) the results of dry year; c) the results of flood year. The red, blue and green represent Xuying, Xixia, Zhangying monitoring sites respectively. at the Xixia hydrological station during the normal season and the dry season are approximately 63.2 and $11.7 \%$, respectively. The COD does not meet the requirement in the three seasons. The probability of COD non-compliance at the Xixia hydrological station is approximately $92.9 \%$ during the normal season and approximately $99.7 \%$ during the dry season. The other two stations meet the requirement during the normal season and the dry season. During the wet season, however, there is a probability of COD non-compliance at the three stations; the probability of COD non-compliance is approximately $11.4 \%$ at the Xuying monitoring site, approximately $69.8 \%$ at the Xixia hydrological station and approximately $75.5 \%$ at the Zhangying monitoring site (Table S4).

\section{(4) Scenario 4: 50\% increase in pollutant discharge}

The possibility of non-compliance is especially serious when the pollutants increase by $50 \%$ during a flood year. COD exceeds the standard at most of the sites for the entire year. During the normal season, the probability of COD non-compliance is approximately $98.9 \%$ at the Xixia hydrological station and approximately $98.9 \%$ at the Zhangying monitoring site. During the dry season, the probability of COD non-compliance is approximately $1 \%$ at the Xuying monitoring site, approximately $99.7 \%$ at the Xixia hydrological station, and approximately $58.2 \%$ at the Zhangying monitoring site. During the wet season, the probability of COD non-compliance is approximately $44.1 \%$ at the Xuying monitoring site, approximately $81.9 \%$ at the Xixia hydrological station, and approximately $89 \%$ at the Zhangying monitoring site (Figure 15, Table S6).

When the pollution increases by $50 \%$ during a dry year, all three pollutants have the possibility of exceeding the level-II standard during the normal season. The probability of DO noncompliance at the Xixia hydrological station is approximately $25.8 \%$. The probability of $\mathrm{NH}_{3}-\mathrm{N}$ non-compliance is approximately $1.7 \%$ at the Xixia hydrological station and approximately $3.3 \%$ at the Zhangying monitoring site. The probability of COD non-compliance is approximately $98.5 \%$ at the Xixia hydrological station and approximately $98.5 \%$ at the Zhangying monitoring site. During the dry season, DO at the Xixia hydrological station has a probability of non-compliance of $0.6 \%$. During the wet season, the COD may exceed the standard at all three monitoring sites; the probability of non-compliance is approximately $39.6 \%$ at the Xuying monitoring site, approximately $77.7 \%$ at the Xixia hydrological station, and approximately $86.5 \%$ at the Zhangying monitoring site (Table S6).

When the pollutants increased by $50 \%$ during a level year, only $\mathrm{NH}_{3}-\mathrm{N}$ met the water quality requirement at the entry to the Danjiangkou Reservoir for the entire year. The probability of COD non-compliance during the wet season is approximately $45.4 \%$ at the Xuying monitoring site, approximately $79.6 \%$ at the Xixia hydrological station, and approximately $87.9 \%$ at the Zhangying monitoring site. DO has the possibility of exceeding the standard during all three hydrological seasons. During the normal season, the probability of noncompliance at the Xixia hydrological station is approximately $9.2 \%$. During the dry season, the probability of non-compliance at the Xixia hydrological station is approximately 1.8\%. During 
the wet season, the probability of non-compliance at the Xuying monitoring site is approximately $13.3 \%$ (Table S6).

\subsection{Actions and Suggestions for Improving the Water Qual- ity of the Laoguanhe River}

The water quality analysis of the Laoguanhe River indicates that the total water quality needs to remain stable. The water quality simulation based on the 2012 data shows that the total water quality is relatively good. The main threats to the water quality originate from the Xuying monitoring site, the Xixia hydrology station and the Zhangying monitoring site, which are situated in the downstream part of the Laoguanhe River. To ensure the water supply of the South-to-North Water Diversion Project, the environment of the Laoguanhe River must be managed to ensure that the water quality requirements of the Danjiangkou Reservoir are met; the water must meet the level-II standard when it enters the reservoir.

Economic measures are important means of environmental management. The water quality of the Laoguanhe River directly affects the water quality of the middle route of the South-to-North Water Diversion Project. Hence, the industrial emissions in the Laoguanhe drainage must be decreased. Projects with large economic benefits that emit less pollution should be developed. In addition, policies should encourage and promote emission reductions. Enterprises that have significantly reduced their pollution emissions could be allowed to sell their rights to release pollution. Because farming is the main economic segment in the Laoguanhe drainage, agricultural pollution is a significant threat to water quality. Therefore, the environmental awareness of farmers should be increased by providing them with economic benefits, and livestock and poultry farmers should be encouraged to build facilities to treat animal waste. Economic benefits should be given to farmers who decrease their use of fertilizer and to regions that return agricultural fields to forests and reduce water loss and soil erosion. The eco-compensation fund should only be used for ecological
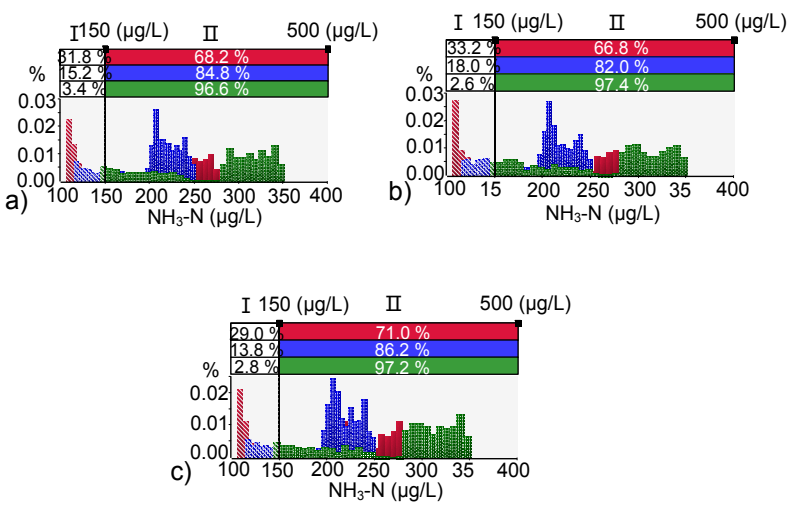

Figure 15. Results for a $50 \%$ increase of pollutants in different hydrological years (set $\mathrm{NH}_{3}-\mathrm{N}$ in wet season as examples). a) the results of level year; b) the results of dry year; c) the results of flood year. The red, blue and green represent Xuying, Xixia, Zhangying monitoring sites respectively. environmental protection.

There is presently no modern sewage collection system in the Laoguanhe drainage. Domestic sewage is discharged into ditches and open channels. Most of the villages and towns in the Laoguanhe drainage are located along the river, along roads and near industrial facilities, which are widely distributed, and therefore, the pipe system cannot satisfy the demands of development. The sewage recycling and disposal facility should be completed, and residents should be encouraged to use the waste transfer station and appropriately dispose of domestic sewage and rubbish. The development of livestock and poultry breeding should encourage intensive recycling and harmless and ecologically responsible breeding

Most of the polluters in the Laoguanhe drainage are located in Xixia County and Xichuan County, and the corresponding reaches of the river extend from the Xuying reach to the Zhangying reach. Thus, these drainages have the highest water quality risks. The management of the pollution discharge outlets of rivers must be increased to ensure the smooth implementation of the middle route of the South-to-North Water Diversion Project. Even though there is little industry in the middle and upper reaches of the Laoguanhe River, most domestic sewage is discharged without any treatment, which adversely affects water quality. In addition, there are too few water quality monitoring sites to allow for effective water quality management. The main method for managing water quality in this drainage is thus to optimize the water quality monitoring network. Comprehensive planning is also an important method to guarantee the safety of the water environment. The Laoguanhe River is an important upstream tributary of the Danjiangkou Reservoir, and its water quality directly affects the water quality of the reservoir. The most effective way to enhance the comprehensive management of water quality is to develop strict drainage water plans and environmental targets.

\section{Conclusions}

In this study, the calibration of the traditional QUAL2Kw model was enhanced by improving the goodness-of-fit objecttive function using a Markov process and a latin hypercube sampling approach. The developed method improves upon previous studies by (1) allowing water quality simulations with sparse data, and (2) considering uncertain parameters in the simulation process. The method was then applied to the Laoguanhe River, which is the closest upstream tributary of the Danjiangkou Reservoir to the Taocha diversion canal. The results indicate that the improved simulation model can provide valid support for water quality management and decision-making. The water quality analysis of the Laoguanhe River indicates that the water quality of the river is gradually improving, and a simulation based on 2012 data from the Laoguanhe River shows that the water quality is quite good. The main pressures on the water quality are from the Xuying, Xixia and Zhangying monitoring sites, which are located along the lower reaches of the Laoguanhe River. To ensure the smooth operation of the middle route of the South-to-North Water Diversion Project, water management measures must be taken to ensure that the water of the Lao- 
guanhe River meets the class-II requirements at the entry to the Danjiangkou Reservoir. However, due to the lack of data from the Laoguanhe River basin, the data ranges that were used to calibrate the parameters were based on foreign and domestic experience. Because integral water quality data can only use maximum and minimum data for model calibration, the validation errors at some of the monitoring sites are large. Future research will include the uncertainty of the initial water quality in the analysis of water quality risk.

Acknowledgments. This research was supported by National Key Research and Development Program (2016YFC0401302) and the National Water Pollution Control and Treatment Science and Technology Major Project (2017ZX07301-001). We would like to extend special thanks to the editor and the anonymous reviewers for their valuable comments in greatly improving the quality of this paper.

\section{References}

Cai, Y.P., Huang, G.H., Yang, Z.F., and Tan, Q. (2009a). Identification of optimal strategies for energy management systems planning under multiple uncertainties. Appl. Energy, 86(4), 480-495. https:// doi.org/10.1016/j.apenergy.2008.09.025

Cai, Y.P., Huang, G.H., Yang, Z.F., Lin, Q.G., and Tan, Q. (2009b). Community-scale renewable energy systems planning under uncertainty - An interval chance-constrained programming approach. Renew. Sustain. Energy Rev., 13(4), 721-735. https://doi.org/10.1016/j.rser. 2008.01.008

Cai, Y.P., Huang, G.H., Tan, Q., and Liu, L. (2011). An integrated approach for climate-change impact analysis and adaptation planning under multi-level uncertainties. Part II. Case study. Renew. Sustain. Energy Rev., 15(6), 3051-3073. https://doi.or/10.1016/j.rser. 2011.03.014

Camargo, R.A., Calijuri, M.L., Santiago, A.F., Couto, E.A., and Silva, M.M. (2010). Water quality prediction using the QUAL2Kw model in a small karstic watershed in Brazil. Acta Limnologica Brasiliensia. 22(4), 486-498. https://doi.org/10.4322/ac-talb.2011.012

Chen, X.F., Jiang, S.Y., and Han, P. (2012). Environmental risk assessment for the Laoguanhe River using fuzzy analytic hierachy process approach (in Chinese). South-to-North Water Div. Water Sci. Technol., 10(3), 87-97.

Cho, J.H. and Ha, S.R. (2010). Parameter optimization of the QUAL2K model for a multiple-reach river using an influence coefficient algorithm. Sci. Total Environ., 408(8), 1985-1991. https://doi.org/10. 1016/j.scitotenv.2010.01.025

Cohen, D., Shamir, U., and Sinai, G. (2004). Water quality aspects of optimal operation of rural water distribution systems for supply of irrigation and drinking water. Irrig. Drain., 53(4), 339-361. https://doi. org/10.1002/ird.143

Cox, B.A. (2003). A review of currently available in-stream waterquality models and their applicability for simulating dissolved oxygen in lowland rivers. Sci. Total Environ., 314, 335-377. https://doi. org/10.1016/S0048-9697(03)00063-9

Department of Ecology of the State of Washington. (2017). Models for Total Maximum Daily Load Studies. http://www.ecy.wa.gov/programs/eap/models.html

Dong, C., Tan, Q., Huang, G.H., and Cai, Y.P. (2014). A dual-inexact fuzzy stochastic model for water resources management and nonpoint source pollution mitigation under multiple uncertainties. Hydrol. Earth Syst. Sci., 18(5), 1793-1803. https://doi.org/10.5194/hess18-1793-2014

Kort, I.T. and Booij, M.J. (2007). Decision making under uncertainty in a decision support system for the Red River. Environ. Model. Softw., 22(2), 128-136. https://doi.org/10.1016/j.envsoft.2005.07.014

Fan, C., Ko, C.H., and Wang, W.S., (2009). An innovative modeling approach using Qual2K and HEC-RAS integration to assess the impact of tidal effect on River Water quality simulation. J. Environ. Manage., 90(5), 1824-1832. https://doi.org/10.1016/j.jenvman.2008. 11.011

Fan, F.M., Fleischmann, A.S., Collischonn, W., Ames, D.P., and Rigo, D. (2015). Large-scale analytical water quality model coupled with GIS for simulation of point sourced pollutant discharges. Environ. Model. Software, 64, 58-71. https://doi.org/10.1016/j.envsoft.2014. 11.012

Fan, Y.R. and Huang, G.H. (2012). A robust two-step method for solving interval linear programming problems within an environmental management context. J. Environ. Inf., 19(1), 1-9. https:// doi.org/10.3808/jei.201200203

Fan, Y.R., Huang, G.H., Baetz, B.W., Li, Y.P., and Huang, K. (2017a). Development of a copula-based particle filter (coppf) approach for hydrologic data assimilation under consideration of parameter interdependence. Water Resour. Res., 53(6). https://doi.org/10.1002/2016 WR 020144

Fan, Y. R., Huang, G.H., Baetz, B.W., Li, Y.P., Huang, K., and Chen, X., et al. (2017b). Development of integrated approaches for hydrological data assimilation through combination of ensemble kalman filter and particle filter methods. J. Hydrol., https://doi.org/10.1016/ j.jhydrol.2017.05.010

Gallagher, M. and Doherty, J. (2007). Parameter estimation and uncertainty analysis for a watershed model. Environ. Model. Software, 22(7), 1000-1020. https://doi.org/10.1016/j.envsoft.2006.06.007

Harmel, R. and Smith, P. (2007). Consideration of measurement uncertainty in the evaluation of goodness-of-fit in hydrologic and water quality modeling. J. Hydrol., 337(3-4), 326-336. https://doi.org/10. 1016/ j.jhydrol.2007.01.043

Helton, J.C. and Davis, F.J. (2003). Latin hypercube sampling and the propagation of uncertainty in analyses of complex systems. Reliab. Eng. Syst. Saf., 81(1), 23-69. https://doi.org/10.1016/S0951-8320 (03)00058-9

Huang, G.H. and Cao, M.F. (2011). Analysis of solution methods for interval linear programming. J. Environ. Inf., 17(2), 54-64. https://doi. org/10.3808/jei.201100187

Kannel, P.R., Lee, S., Kanel, S.R., Lee, Y.S., and Ahn, K.H. (2007a). Application of QUAL2Kw for water quality modeling and dissolved oxygen control in the river Bagmati. Environ. Monit. Assess., 125 (1-3), 201-217.

Kannel, P.R., Lee, S., Lee, Y.S., Kanel, S.R., and Pelletier, G.J. (20 07b). Application of automated QUAL2Kw for water quality modeling and management in the Bagmati River, Nepal. Ecol. Model., 202(3-4), 503-517. https://doi.org/10.1016/j.ecolmodel.2006.12.033

Legates, D.R. and McCabe, G.J. (1999). Evaluating the use of "goodness-of-fit" Measures in hydrologic and hydroclimatic model validation. Water Resour. Res., 35(1), 233-241. https://doi.org/10.1029/ 1998WR900018

Lindenschmidt, K.E. (2006). The effect of complexity on parameter sensitivity and model uncertainty in river water quality modelling. Ecol. Model., 190(1-2), 72-86. https://doi.org/10.1016/j.ecolmo-del. 2005.04.016

Liu, J., Li, Y.P., Huang, G.H., Zhuang, X.W., and Fu, H.Y. (2017). Assessment of uncertainty effects on crop planning and irrigation water supply using a monte carlo simulation based dual-interval stochastic programming method. J. Cleaner Prod., 149, 945-967. https://doi.org/10.1016/j.jclepro.2017.0 2.100

Li, Y.P., Huang, G.H., and Chen, X. (2011). Planning regional energy system in association with greenhouse gas mitigation under uncertainty. Appl. Energy, 88(3), 599-611. https://doi.org/10.1016/ 
j.apenergy.2010.07.037

Li, Y.P., Huang, G.H., Huang, Y.F., and Zhou, H.D. (2009). A multistage fuzzy-stochastic programming model for supporting sustainable water-resources allocation and management. Environ. Model. Software, 24(7), 786-797. https://doi.org/10.1016/j.envsoft. 2008.11.008

Maity, R. (2012). Probabilistic assessment of one-step-ahead rainfall variation by Split Markov Process. Hydrol. Process., 26(21), 31823194. https://doi.org/10.1002/hyp. 8245

Manache, G. and Melching, C.S. (2008). Identification of reliable regression- and correlation-based sensitivity measures for importance ranking of water-quality model parameters. Environ. Model. Softw., 23(5), 549-562. https://doi.org/10.1016/j.envsoft.2007.08.001

Melching, C.S. and Yoon, C.G. (1996). Key sources of uncertainty in QUAL2E model of Passaic river. J. Water Resour. Plann. Manage., 122(2), 105-113. https://doi.org/10.1061/(ASCE)0733-9496(1996) 122:2(105)

Minasny, B. and McBratney, A.B. (2006). A conditioned Latin hypercube method for sampling in the presence of ancillary information. Comput. Geosci., 32(9), 1378-1388. https://doi.org/10.1016/j. cageo.2005.12.009

Nakhaei, N. and Etemad-Shahidi, A. (2012). Applying Monte Carlo and classification tree sensitivity analysis to the Zayandehrood River. J. Hydroinf., 14(1), 236-250. https://doi.org/10.2166/hydro.20 11.094

Oliveira, B., Bola, J., Quinteiro, P., Nadais, H., and Arroja, L. (2012). Application of Qual2Kw model as a tool for water quality management: Cértima River as a case study. Environ. Monit. assess. 184(10), 6197-6210. https://doi.org/10.1007/s106-61011-2413-z

Pelletier, G.J., Chapra, S.C., and Tao, H. (2006). QUAL2Kw - A framework for modeling water quality in streams and rivers using a ge- netic algorithm for calibration. Environ. Model. Softw., 21(3), 419- 425. https://doi.org/10.1016/j.envsoft.2005.07.002

Sun, J., Li, Y.P., Huang, G.H., and Wang, C.X. (2017). Analysis of interactive effects of DEM resolution and basin subdivision level on runoff simulation in kaidu river basin, china. Hydrol. Res., 48(4). https://doi.org/10.2166/nh.2016.332

Shen, Z.Y., Hong, Q., Yu, H., and Liu, R.M. (2008). Parameter uncertainty analysis of the non-point source pollution in the Daning River watershed of the Three Gorges Reservoir Region, China. Sci. Total Environ., 405(1-3), 195-205. https://doi.org/10.1016/j.scitotenv. 2008.06.009

Takyi, A.K., and Lence, B.J. (1995). Markov chain model for seasonal-water quality management. J. Water Resour. Plann. Manage., 121(2), 144-157. https://doi.org/10.1061/(ASCE)0733-9496(1995) 121:2(144)

Tan, Q., Huang, G.H., Wu, C.Z., and Cai, Y.P. (2011a). IF-EM: An interval-parameter fuzzy linear programming model for environmentoriented evacuation planning under uncertainty. J. Adv. Transport., 45(4), 286-303. https://doi.org/10.1002/atr.137

Tan, Q, Huang, G.H., and Cai, Y.P. (2011b). Radial interval chanceconstrained programming for agricultural non-point source water pollution control under uncertainty. Agric. Water Manage., 98(10), 1595-1606. https://doi.org/10.1016/j.agwat.2011.05.013

Wang, J.P., Su, B.L., Jia, H.F., Cheng. S.T., Yang, C., Wu, D.W., and Sun, F., (2006). Integrated model of nutrients for the Miyun Reservoir and its watershed (in Chinese). Environ. Sci., 27, 1286-1291.

Wang, L., Huang, G., Wang, X., and Zhu, H. (2018). Risk-based electric power system planning for climate change mitigation through multi-stage joint-probabilistic left-hand-side chance-constrained fractional programming: a canadian case study. Renew. Sustain. Energy Rev., 82, 1056-1067. https://doi.org/10.1016/j.rser.2017.09.098 